\title{
PENERAPAN TEKNIK SEO (SEARCH ENGINE OPTIMIZATION) PADA WEBSITE DALAM STRATEGI PEMASARAN MELALUI INTERNET
}

\author{
Rony Baskoro Lukito; Cahya Lukito; Deddy Arifin \\ Computer Science Department, School of Computer Science, Binus University \\ Jl. K.H. Syahdan No. 9, Palmerah, Jakarta Barat 11480 \\ Email: rbaskoro@binus.edu
}

\begin{abstract}
The purpose of this research is how to optimize a web design that can increase the number of visitors. The number of Internet users in the world continues to grow in line with advances in information technology. Products and services marketing media do not just use the printed and electronic media. Moreover, the cost of using the Internet as a medium of marketing is relatively inexpensive when compared to the use of television as a marketing medium. The penetration of the internet as a marketing medium lasted for 24 hours in different parts of the world. But to make an internet site into a site that is visited by many internet users, the site is not only good from the outside view only. Web sites that serve as a medium for marketing must be built with the correct rules, so that the Web site be optimal marketing media. One of the good rules in building the internet site as a marketing medium is how the content of such web sites indexed well in search engines like google. Search engine optimization in the index will be focused on the search engine Google for $83 \%$ of internet users across the world using Google as a search engine. Search engine optimization commonly known as SEO (Search Engine Optimization) is an important rule that the internet site is easier to find a user with the desired keywords.
\end{abstract}

Keywords: SEO, search engine optimization, internet marketing, google, search engine, page rank.

\begin{abstract}
ABSTRAK
Jumlah pengguna internet di seluruh dunia terus bertambah dan akan terus tumbuh seiring dengan kemajuan teknologi komunikasi. Media pemasaran produk maupun jasa bukan Cuma pada media cetak dan elektronik.Saat ini pemasaran juga dilakukan menggunakan media internet. Penetrasi internet yang melewati batas negara menjadi salah satu kekuatan internet sebagai media pemasaran. Terlebih lagi, biaya penggunaan internet sebagai media pemasaran relatif murah jika dibandingkan dengan penggunaan televisi sebagai media pemasaran. Penetrasi internet sebagai media pemasaran berlangsung selama 24 jam di berbagai penjuru dunia. Tapi untuk membuat sebuah situs internet menjadi situs yang banyak dikunjungi oleh pengguna internet, situs tersebut tidak hanya baik dari tampilan luar saja. Situs internet yang dijadikan sebagai media pemasaran harus dibangun dengan kaidah-kaidah yang benar, sehingga situs internet tersebut menjadi media pemasaran yang optimal. Salah satu kaidah-kaidah yang baik dalam membangun situs internet sebagai media pemasaran adalah bagaimana isi dari situs internet tersebut terindex dengan baik di mesin pencari seperti google. Optimasi pada index mesin pencari akan difokuskan pada mesin pencari google karena 83\%pengguna internet di seluruh dunia menggunakan google sebagai mesin pencarinya. Optimasi pada mesin pencari yang lebih dikenal sebagai SEO (Search Engine Optimization) merupakan kaidah penting agar situs internet lebih mudah dicari pengguna dengan kata kunci yang diinginkan.
\end{abstract}

Kata kunci: SEO, optimasi mesin pencari, pemasaran melalui internet, google, mesin pencari 


\section{PENDAHULUAN}

Information technology berkolaborasi dengan communication technology menjadikan akses internet (interconnection networking) mudah dan murah. Perpaduan kedua teknologi ini yang lebih dikenal dengan istilah ICT (Information and Communication Technology) telah menjadi sebuah media yang sangat akrab dengan masyarakat modern sekarang ini. Di era informasi saat ini ditandai dengan kemudahan mengakses informasi, terutama internet, telah menjadi salah satu sarana media pemasaran. Pemasaran dengan menggunakan media internet, selain efektif juga dapat menekan biaya apabila dibandingkan dengan media televisi. Bukan hanya itu, selain relatif murah jangkauannya juga merambah ke seluruh dunia. Sebagai konsekuensi telah meratifikasi World Summit on the Information Society (WSIS) di Swiss pada bulan Desember tahun 2003 Indonesia, pada tahun 2015, setidaknya lebih dari separuh penduduk dunia harus dapat menikmati koneksi internet. (International Telecommunication Report, 2010).

Saat ini di perkirakan jumlah pengguna internet seluruh dunia sebanyak 2,4 miliar orang, dengan tingkat pertumbuhan sebanyak 8 persen, yang didorong di negara-negara berkembang. Jumlah pengguna ini menunjukkan rasio penetrasi populasi 23 persen dari total populasi. Data ini terungkap dari paparan slide, yang dipresentasikan Mary Meeker, seorang managing director Morgan Stanley, sebagai kepala riset teknologi global di institusi itu dalam sebuah acara di Stanford University. Hasil survei menunjukkan pertumbuhan penggunaan Internet di Indonesia terus meningkat. Di tahun 2012, penetrasi penggunaan Internet di wilayah urban Indonesia mencapai 24,23\% (MarkPlus, 2012). Jumlah ini merupakan potensi luar biasa jika dibandingkan dengan jumlah penduduk Indonesia yang mencapai 260 juta jiwa dan juga merupakan jumlah yang sangat besar bila dibandingkan dengan penetrasi Internet di negara-negara sekitar Indonesia. Baik di Asia Tenggara maupun Australia (MarkPlus, 2012)

Seberapa penting SEO dalam internetmarketing? Jika usaha yang mengandalkan internet (bisnis online) maka SEO sangat penting dan juga menjadi penting, jika usaha mencari pasar lain melalui penetrasi internet. Mencari pasar lewat internet bukan sekedar memasarkan lewat media internet. Tapi jauh lebih dari itu adalah bagaimana menarik pengunjung sebanyak-banyak datang ke website. Jika diibaratkan sebuah toko offline, maka website adalah lokasi strategis yang banyak dilewati orang dan terkenal dengan kualitas barang dan jasa yang dijual. Jadi peran marketing dalam menarik pengunjung sebanyak-banyaknya merupakan hal yang penting dan peran SEO dalam internet juga penting agar pengunjung bisa datang sebanyak-banyaknya.

\section{Tinjauan Pustaka}

\section{Internet}

Internet merupakan sebuah revolusi dalam bidang teknologi pada abad 21 yang menyatukan dua teknologi telekomunikasi dan komputer. Kedua teknologi ini kemudian dikenal sebagai ICT (Information and Communication Technology). Perkembangan pesat internet dimulai dengan dibuatnya sebuah aplikasi World Wide Web oleh Berners-Lee dan timnya pada tahun 1990. Situs web pertama yang dibuat Berners-Lee beralamat di http://info.cern.ch/ dan dimasukkan online untuk pertama kalinya pada 6 Agustus 1991. Lee lantas meluncurkan browser-nya pada tahun 1991. (Berners-Lee, Cailliau, Groff, \& Pollermann, 1992). Orang pertama yang memperkenalkan WWW adalah Marc Andressen dengan meluncurkan sebuah browser dengan nama Mosaic, beberapa tahun setelah Lee meluncurkan browsernya. Pada 1994, Berners-Lee mendirikan World Wide Web Consortium (W3C) di Massachusetts Institute of Technology.Marc Andersen lantas mendirikan Netscape.Sejak saat itu pengguna internet dan WWW berkembang dengan sangat pesat hingga saat ini. 


\section{Marketing}

Dalam bukunya Essentials of Marketing Jim Blythe, mengatakan bahwa marketing adalah istilah yang diberikan pada semua aktifitas yang terjadi antara organisasi/perusahaan dengan pelanggan.Ini merupakan konsep mendasar dari sebuah pasar, di mana penjual dan pembeli datang bersama-sama untuk melakukan transaksi (atau pertukaran) yang saling menguntungkan. (Blythe, 2005). Dua istilah lain dari pemasaran yang paling banyak digunakan adalah: (1) Pemasaran adalah proses manajemen yang mengidentifikasi, mengantisipasi, serta memenuhi kebutuhan pelanggan secara efisien dan menguntungkan. (UK Chartered Institute of Marketing). (2) Pemasaran adalah proses perencanaan dan konsep pelaksanaan, penetapan harga, promosi dan distribusi gagasan atas barang dan jasa untuk menciptakan pertukaran dalam rangka memenuhi kebutuhan individu dan organisasi. (American Marketing Association )

\section{Internet Marketing}

Internet marketing juga dikenal sebagai digital marketing, web marketing, online marketing atau e-marketing. Jones, Malczyk, \& Beneke (2011) mengatakan:

“ Internet marketing - often called online marketing or eMarketing - is essentially any marketing activity that is conducted online through the use of internet technologies. It comprises not only advertising that is shown on websites, but also other kinds of online activities like email and social networking. Every aspect of internetmarketing is digital, meaning that it is electronic information that is transmitted on a computer or similar device, though naturally it can tie in with traditional offline advertising and sales too"

Jadi setiap kegiatan pemasaran yang dilakukan secara online dengan menggunakan teknologi internet adalah internet marketing. Termasuk aktivitas online seperti e-mail dan jejaring sosial.

Lebih lanjut Jones, Malczyk, \& Beneke (2011) mengatakan bahwa ada tiga prinsip dasar dari internet marketing yaitu: (1) Immediacy. Perubahan yang cepat dan up to date dalam waktu per menit termasuk menanggapi secara online. (2) Personalisation. Pelanggan harus dapat ditanggapi dan dilayani secara personal tidak lagi sama untuk semua pelanggan. Gunakan informasi pribadi secara online yang dimasukkan pelanggan sebagai keuntungan perusahaan. (3) Relevance. Komunikasi online harus dibuat menarik dan mengetahui bagaimana cara agar pelanggan merasa dilayani seolah-olah disambut kedatangan mereka di pintu.sehingga membuat pelanggan merasa nyaman.

Perbedaan internet marketing dengan marketing tradisional adalah bahwa internet marketing lebih masuk akal, lebih murah, cepat serta menjangkau banyak pelanggan dan merupakan cara terbaik bagi bisnis yang ingin memasuki pasar lokal maupun internasional (Mirzaei, Jaryani, Aghaei, Salehi, \& Saeidinia, 2012).

\section{Search Engine Google}

Pada tahun 1997, BackRub berganti nama menjadi Googol. Namun pada presentasi nama pergantian tersebut Googol diperkenalkan menjadi Google. Ada cerita bahwa pada saat registrasi domain mereka salah ketik yang seharus Googol menjadi Google. Nama ini sekarang terus mendunia. (Google, 2010). Mesin pencari Google menjadi mesin pencari yang menguasai mesin pencari di internet. Berdasarkan survei yang dilakukan Pew Internet (Purcell, Brenner, \& Rainie, 2012) dalam projectnya Search Engine Use 2012 pada Maret 2012 mengatakan:

"Google continues to dominate the list of most used search engines. Asked which search engine they use most often, 83\% of search users say Google. The next most 
cited search engine is Yahoo, mentioned by just 6\% of search users. When we last asked this question in 2004, the gap between Google and Yahoo was much narrower, with $47 \%$ of search users saying Google was their engine of choice and 26\% citing Yahoo."

Google berjalan pada jaringan terdistribusi dari ribuan komputer murah dan dapat melakukan pemrosesan paralel secara cepat. Pemrosesan paralel adalah metode perhitungan di mana banyak perhitungan dapat dilakukan secara simultan, secara signifikan mempercepat pengolahan data. Google memiliki tiga bagian penting: (1) Googlebot, web crawler yang menemukan dan mengambil halaman web. (2) Google Indexer, pengindeks dari setiap kata pada setiap halaman dan menyimpan indeks yang dihasilkan kata dalam database yang besar. (3) Processor query, yang membandingkan permintaan pencarian oleh pengguna ke indeks dan merekomendasikan dokumen yang dianggap paling relevan.

\section{Search Engine Optimization (SEO)}

SEO adalah serangkaian proses yang dilakukan secara sistematis yang bertujuan untuk meningkatkan volume dan kualitas traffic kunjungan melalui mesin pencari menuju situs web tertentu dengan memanfaatkan mekanisme kerja atau algoritma mesin pencari tersebut. Tujuan dari SEO adalah menempatkan sebuah situs web pada posisi teratas, atau setidaknya halaman pertama hasil pencarian berdasarkan kata kunci tertentu yang ditargetkan. Secara logis, situs web yang menempati posisi teratas pada hasil pencarian memiliki peluang lebih besar untuk mendapatkan pengunjung.

Sejalan dengan makin berkembangnya pemanfaatan internet sebagai media bisnis, kebutuhan SEO juga semakin meningkat. Berada pada posisi teratas hasil pencarian akan meningkatkan peluang sebuah perusahaan pemasaran berbasis web untuk mendapatkan pelanggan baru. Peluang ini dimanfaatkan sejumlah pihak untuk menawarkan jasa optimisasi mesin pencari bagi perusahaanperusahaan yang memiliki basis usaha di internet. (Google, 2010)

\section{Tujuan dan Manfaat Penelitian}

Tujuan penelitian ini adalah untuk mengetahui bagaimana merancang sebuah situs internet yang baik agar situs tersebut ramai dikunjungi sesuai dengan target. Sesuai dengan target adalah pengunjung yang ramai mengunjungi tersebut melakukan transaksi. Jadi, merupakan hal penting untuk mencari target yang tepat untuk mengunjungi situs yang dibangun. Dengan pengunjung yang tepat mendatangi situs internet, maka diharapkan akan terjadi transaksi atas barang ataupun jasa yang ditawarkan. Oleh sebab itu, penting sekali memahami bagaimana perilaku pengguna khususnya keyword yang sering digunakan di mesin pencari google. Keyword yang diketikkan oleh pengguna di mesin pencari google dapat diakses secara gratis sebagai bahan analisa untuk merancang situs internet yang baik.

\section{METODE}

Metodologi penelitian yang digunakan adalah menganalisa dari beberapa situs web, apakah sebuah situs web tersebut dibangun menggunakan kaidah SEO yang baik ? Jika saja web itu dibangun menerapkan kaidah $S E O$ yang baik maka jumlah pengunjung harian pasti menggembirakan dan secara tidak langsung akan dapat meningkatkan penjualan. Ketika situs web yang dibangun tidap menerapkan kaidah SEO yang benar, maka jumlah pengunjung akan sedikit, bahkan bertahun-tahun setelah web tersebut diluncurkan. 
Tabel 1 Contoh Situs Web Yang Belum menerapkan SEO

\begin{tabular}{lccc}
\hline \multicolumn{1}{c}{ Web } & Created & SEO & Visitor/day \\
\hline coklatdach.com & Sep-11 & $78 \%$ & $<30$ \\
suvenircoklat.com & Jul-10 & $96 \%$ & $<40$ \\
chocolatemonggo.com & Jan-08 & $75 \%$ & $>100$ \\
ordercoklatdach.com & Jul-12 & $95 \%$ & $<30$ \\
tokocoklatbandung.com & Apr-10 & $87 \%$ & $<30$ \\
\hline
\end{tabular}

Tabel di atas menunjukkan bahwa, dengan usia web yang cukup lama tapi peningkatan jumlah pengunjung belum signifikan. Walaupun ada beberapa web dengan score SEO yang cukup bagus. Dalam penelitian ini, sebuah situs web akan dibangun dengan menerapkan kaidah $S E O$ yang benar, sehingga diharapkan jumlah pengunjung akan cepat bertambah.

\section{HASIL DAN PEMBAHASAN}

\section{Pemilihan Domain}

Langkah awal dalam internet marketing yang cukup penting adalah pemilihan domain. Karena pemilihan domain yang tepat terhadap barang dan jasa yang akan dipasarkan, sangat berpengaruh terhadap pencarian di internet. Mengapa sangat penting? Pertama, penting untuk memprediksi jumlah kata atau keyword yang akan di ketik atau di-click oleh user dari nama domain yang tepat. Kedua, pemilihan domain yang tepat akan membuat pengguna lebih terbiasa terhadap hubungannya dengan produk/jasa yang akan diketik dan di-click. Pada prinsipnya, setiap nama domain yang paling mendekati dengan keyword pencarian maka nama tersebut yang akan ditampilkan oleh Search Engine di posisi atas.

Microsoft dan Univesitas Stanford dalam risetnya Domain Bias in Web Search (2012), membuktikan bahwa pemilihan domain yang tepat akan meningkatkan pencarian pengguna sebanyak 25\% (Ieong, Mishra, Sadikov, \& Li, 2012). Demikian juga riset yang dilakukan SEDO 2011, mengatakan dekripsi domain bisa dijadikan brand new. (Sedo, 2011). Langkah berikutnya adalah penentuan keyword dari keyword utamanya. Keyword utamanya adalah coklat, selanjutnya menentukan turunan keyword dari keyword utamanya. Penentuan keyword yang tepat akan membantu banyak pengguna yang datang ke web. Jones, Malczyk, \& Beneke (2011) mengatakan pemilihan kata kunci yang tepat akan mempromosikan web serta memastikan web secara online sampai pada orang yang tepat.

Google menyediakan tools yang dapat digunakan untuk memprediksi berapa banyak pengguna internet mengetik kata kunci "coklat”. Ini penting sekali karena dari sini dapat diperkirakan berapa besar peluang pengguna datang ke web. Sebagai informasi, dari Kamus Besar Bahasa Indonesia, kata yang benar untuk penulisan coklat adalah "cokelat". Tapi apabila dimasukkan ke dalam keyword planner, kata manakah yang paling banyak di ketik user pada mesin pencari google?

Sekarang keyword "coklat" dan "cokelat" dimasukan dalam tools keyword planner. Sebelumnya juga ditentukan bahwa wilayah pemasarannya hanya Indonesia. Terlihat bahwa, keyword "coklat” diperkirakan sebanyak 9.900 pengguna dan "cokelat” hanya 2.400 pengguna saja dalam sebulan. Lihat juga tingkat kompetisi kedua entry tersebut masih low. Artinya kesempatan untuk mendapatkan pengguna yang datang ke web berdasarkan jumlah pengguna dan tingkat kompetisinya sangatlah besar. Setelah memastikan bahwa keyword "coklat” lebih baik dari pada "cokelat” meskipun dalam Bahasa Indonesia yang benar adalah "cokelat", maka selanjutnya adalah mencari turunan keyword dari coklat itu sendiri. 
Ternyata ada 566 turunan dari keyword coklat. Karena pondokcoklat.com tidak menjual atau tidak menggunakan semua keyword maka haruslah dipilih keyword yang sesuai dengan produk yang dijual atau artikel-artikel yang nanti akan dibuat nantinya. Akhirnya dari 566 turunan keyword dipilih hanya keyword tertentu saja. Perlu diingat bahwa keyword ini akan bisa bertambah sesuai dengan produk yang akan dijual atau artikel yang akan dibuat. Adapun keyword turunan pertama yang dianggap sebagai keyword utama yang dipilih adalah: Pondok Coklat, toko coklat, coklat kesehatan, coklat praline, aneka coklat, coklat dark, coklat untuk kesehatan, coklat import, minuman coklat. Pondok coklat adalah keyword tambahan sebagai "branding” yang diharapkan banyak pengguna yang mengetikkan keyword ini di mesin pencari google.

\section{Meta Tag}

Meta tag merupakan deskripsi dari website yang terdiri dari beberapa keyword utama. Deskripsi Meta tag penting karena Google akan menggunakannya sebagai deskripsi dari halaman web. Menambahkan deskripsi meta tag untuk setiap halaman web merupakan praktik yang baik ketika Google tidak dapat membuat deskripsi yang baik tentang web (Google, 2010). Meta tag yang digunakan adalah "Toko Coklat, PondokCoklat.com. Kami menjual aneka coklat, coklat import, minuman coklat termasuk coklat kesehatan /terapi.”

\section{SEO On Page}

SEOon Page adalah optimasi secara maksimal yang dilakukan pada web itu sendiri.SEOon Page inilah inti dari SEO secara keseluruhan. Beberapa SEOon Page antara lain adalah Pemilihan Template SEO Friendly, Fix Permalink In Posts, Penggunaan Keyword Pada Postingan Halaman Produk atau Artikel, Peletakan Keyword yang Tepat dan Gunakan Gambar Unik.

\section{Pemilihan Template SEO Friendly}

Banyak template untuk website yang ada baik yang free ataupun berbayar. Template berbayar digunakan karena fitur yang ada sudah sangat lengkap untuk situs toko online. WPTOKO versi 3.1. digunakan, ini adalah template berbasis wordpress karena wordpress adalah template blog kepunyaan google. Selain template juga digunakan meta tag yang sesuai. Seperti yang telah dibahas sebelumnya, akan ditempatkan Meta tag sebagai meta description agar google tidak mengalami kesulitan untuk membuat deskripsi yang baik untuk web.

\section{Fix Permalink in Posts}

Gunakan permalink yang sesuai dengan produk yang dibahas pada suatu halaman web. Jadi permalink yang sudah dibuat otomatis oleh wordpress, diganti menggunakan kata-kata. Secara default permalink pada postingan adalah seperti ini Permalink: http://pondokcoklat.com/56748 menjadi http://pondokcoklat.com/coklat-silverqueen-bites-almond. Usahakan permalink cukup unik tidak sama dengan produk sejenis yang dijual di toko online lainnya karena google lebih menyukai permalink yang unik.

\section{Penggunaan Keyword pada Postingan Halaman Produk atau Artikel}

Untuk setiap halaman web yang berisi artikel maupun postingan produk harus diberi keyword yang tepat. Pemilihan keyword yang tepat akan diimplementasikan pada posting-an di halaman web. Jadi setiap posting-an halaman web harus berisi satu atau lebih keyword hasil dari Google Keyword Planner.

\section{Peletakan Keyword yang Tepat}

Ada beberapa panduan dalam peletakan keyword sesuai kaidah SEO pada posting-an, baik itu di produk maupun artikel, antara lain (Vaughan, 2008): (1) Judul postingan produk atau artikel harus 
menggunakan keyword. (2) Link artikel harus berisi keyword. Contoh pada permalink. (3) Meta tag/Meta Description harus berisi keyword. (4) Judul artikel harus menggunakan keyword. (5) Paragraf pertama dari artikel harus berisi keyword. (6) Menggunakan gambar unik yang telah di alt tag dengan keyword.

\section{Gunakan Gambar Unik}

Dalam kaidah SEO, untuk mendapat nilai yang baik di mata mesin pencari, harus menggunakan gambar-gambar yang unik, jadi gambar yang dimasukkan belum ada di website lain. Usahakan gambar-gambar tersebut adalah kreasi dari perancang/pemilik web kecuali memang jika tidak dapat membuat gambar sendiri. Sebenarnya, ada layanan dari internet yang menyediakan gambar-gambar walaupun untuk keanggotaannya harus berbayar. Di pondokcoklat.com, hampir semua gambar produk yang dipajang menggunakan gambar yang dibuat sendiri, kecuali untuk artikel dan beberapa produk saja.

\section{Percepat Waktu Loading Halaman Web}

Template yang digunakan wptoko versi 3.1 adalah template yang kemampuan loading-nya cukup cepat. Web di-hosting di hostgator, salah satu hosting yang cukup cepat. Gambar-gambar yang digunakan juga gambar-gambar yang berukuran tidak besar karena untuk menghindari waktu loading yang lama.

\section{Banyaknya Indeks yang Dihasilkan}

Untuk melihat indeks yang ada pada suatu web tinggal ketik saja perintah " site:xyz.com” pada address URL. Dengan memasukkan perintah "site:pondokcoklat.com”, maka diperoleh indeks sebanyak 212 indeks. Semakin banyak banyak indeks, maka semakin baik.Artinya jika produk terus ditambahkan untuk dijual maka indeks yang dihasilkan juga semakin banyak.

\section{Hasil ScoreSEO}

Berapa SEO score yang diperoleh web pondokcoklat.com dengan menerapkan hal-hal yang disebutkan diatas? Banyak tools yang tersedia gratis yang dapat digunakan untuk menghitung score SEO dari suatu web, salah satunya adalah whois.domaintools.com. Hasil dari perhitungan yang dilakukan oleh whois.domaintools.com dapat dilihat pada gambar 1.



Gambar 1 Score SEO pada pondokcoklat.com 
Terlihat pada Gambar 1, Score SEO pada pondokcoklat.com sebesar 91\%. Nilai yang sangat baik, artinya pondokcoklat.com telah dibuat dengan kaidah $S E O$ yang benar.

\section{Hasil Analisa Trafik Kunjungan}

Berdasarkan hasil dari flag counter yang kita gunakan di web untuk menghitung besarnya kunjungan. Domain pondokcoklat.com di beli pada tanggal 22 Februri 2013. Gambar 2 memperlihatkan pada Juli 2013, hanya membutuhkan waktu empat bulan saja, pengunjung uniknya sudah mencapai 87-190 pengunjung per hari. Jumlah pengunjung ini murni dari implementasi SEO tanpa menggunakan back link.

\begin{tabular}{|c|c|}
\hline Page: $\langle 12345\rangle$ & \\
\hline Date & New Visitors \\
\hline July 19, 2013 & 159 \\
\hline July 18,2013 & 190 \\
\hline July 17,2013 & 188 \\
\hline July 16,2013 & 157 \\
\hline July 15,2013 & 161 \\
\hline July 14,2013 & 142 \\
\hline July 13,2013 & 127 \\
\hline July 12,2013 & 156 \\
\hline July 11,2013 & 134 \\
\hline July 10,2013 & 150 \\
\hline July 9, 2013 & 151 \\
\hline July 8,2013 & 113 \\
\hline July 7, 2013 & 97 \\
\hline July 6,2013 & 87 \\
\hline July 5, 2013 & 118 \\
\hline July 4, 2013 & 142 \\
\hline July 3, 2013 & 104 \\
\hline July 2, 2013 & 121 \\
\hline July 1,2013 & 107 \\
\hline June 30,2013 & 107 \\
\hline
\end{tabular}

\section{Position in Google Search Engine On Certain Keyword}

Walaupun belum berada di halaman pertama tapi posisi pondokcoklat.com pada keyword "coklat delfi” yang di-search sebelum 31 Juli 2013 sudah berada di posisi 13. Sudah sangat baik mengingat umur web belum genap 4 bulan.

\section{SIMPULAN}

Dari hasil penelitian tentang Penerapan Teknik SEO (Search Engine Optimization) pada Website dalam Strategi Pemasaran Melalui Internet ini dapat disimpulkan sebagai berikut: (1) Rancangan website yang baik sesuai dengan kaidah SEO dapat meningkatkan traffic kunjungan dalam waktu yang relatif cepat (beberapa bulan). (2) Target pengguna internet yang sesuai dengan target pemasaran akan meningkatkan penjualan barang /jasa. 


\section{DAFTAR PUSTAKA}

Berners-Lee, T., Cailliau, R., Groff, J.-F., Pollermann, B. (1992). World-Wide Web: The Information Universe. Electronic Networking: 52-58.

Blythe, J. (2005). Essentials of Marketing. England: Pearson Education Limited.

Google. (2010). Search Engine Optimization Starter Guide. Diakses pada November 2013, dari Google Inc.: www.google.com

Ieong, S., Mishra, N., Sadikov, E., Li, Z. (2012). Domain Bias in Web Search. Proceedings of the Fifth International Conference on Web Search and Web Data Mining. 413-422. Seattle: ACM.

International Telecommunication Report. (2010). Monitoring The WSIS Targets. Geneva: World Telecommunication/ICT Development Report.

Jones, A., Malczyk, A., Beneke, J. (2011). InternetMarketing;A highly practical guide to every aspect of internetmarketing. GetSmarter.

MarkPlus. (2012). Profil Pengguna Internet Indonesia. Jakarta: APJII.

Mirzaei, H., Jaryani, E., Aghaei, M., Salehi, M., Saeidinia, M. (2012). Differences of "Traditional Marketing" in opposition to "Electronic. 2012 International Conference on Economics, Business and Marketing Management. Singapore: IACSIT Press.

Purcell, K., Brenner, J., Rainie, L. (2012). Search Engine Use 2012. A Project of the Pew Research Center. Washington, D.C.: Pew Research Center’s Internet\& American Life Project.

Sedo. (2011). Domain Names Opportunities and Applications for Marketing Online. Diakses pada November 2013, dari Sedo: www.sedo.com

Vaughan, P. (2008). The Essential Step-By-Step Guide To Internet Marketing. Hubspot. 